\title{
The numerical simulation of GCr15 YRT ring during quenching and deep cryogenic treatment
}

\author{
Sier Deng ${ }^{1,2, a}$, Lehang Zang ${ }^{1, b}$, Wenhu Zhang ${ }^{3, c}$, Xiuhua Shao $^{4, d}$ \\ 1.School of Mechatronics Engineering, Henan University of Science and Technology, Luoyang \\ 471003, China \\ 2.Collaborative Innovation Center of Major Machine Manufacturing in Liaoning, Dalian 116024, \\ China
}

3. School of Mechatronics Engineering, Northwestern Polytechnical University, Xi'an 710071, China 4. Luo Yang Hong Yuan Bearing Limited Company, Luoyang 471132, China a.dse@haust.edu.cn, b.845838970@qq.com,c.526916105@qq.com,d.1786721535@qq.com

Keywords: Quenching; DCT; Residual stress; Residual austenite; Residual martensite Abstract: The temperature-microstructure-stress/strain coupling model of YRT inner ring in the process of oil quenching and deep cryogenic treatment (DCT) were established to study the change rule of cooling process, microstructure evolution and residual stress distribution in the process of oil quenching and DCT. The results provided the theoretical guidance for heat treatment process of YRT inner ring.

\section{Introduction}

Rolling bearing ring and rolling element bear high contact stress and slipping on the contact surface between rings and rolling element, when bearing is working. The repeated force is the mainly reason to cause the decreasing precision, tired flaking, bearing vibration, etc. which reduce bearing service life directly. The performance and reliability of rolling bearing mainly depends on the material. Quenching is one of the important means to improve hardness and wear resistance of rolling bearing, and DCT as a supplementary treatment process after quenching further improve the bearing hardness, wear resistance, strength, corrosion resistance, etc. Because the process of quenching and DCT are complicated and changeable, the traditional testing technology with significant limitations can not accurately and efficiently measure many phenomena and problems in the process of quenching and DCT. Therefore, in industrial production, quenching and DCT still rely on experience and repeated experiments. The too long test period and lots of manpower and resources are the major problems in the development of heat treatment. The research about quenching and DCT inevitably become the focus of the domestic and overseas experts.

With the development of computer application, the combination of heat treatment and computer become the inevitable trend of heat treatment. The international and domestic experts make many extensive research about this: Stickels $\mathrm{C}^{[1]}$ used X-ray diffraction to measure and analyze the specimen's phase transformation. Kwun $\mathrm{S} \mathrm{I}^{[2,3]}$ studied the quenched bearing steel's low cycle fatigue behavior by transmission electron microscopy, stress relaxation, X-ray diffraction line broadening and strain-controlled fatigue testing. Denis $\mathrm{S}^{[4]}$ used the finite element technique to analyze the relation between internal stress and phase transformation. Lisic $\mathrm{B}^{[5]}$ used the specimens' dates after quenching to analyze the quenching intensity and hardness distribution through computer aided. $\mathrm{CHANG}^{[6]}$ measured and analyzed the change of material's residual stress before and after 
the pulsed magnetic treatment by eddy current testing. Gur $\mathrm{C} \mathrm{H}^{[7]}$ used the computer program that is written in Fortran langue to study the internal stress and the inhomogeneous plastic deformation. Simsir $C^{[8]}$ used the three-dimensional finite element method to simulate the process of quenching and study the influence between the irregular model and residual stress distribution. Lee $\mathrm{K} \mathrm{O}^{[9]}$ used the double-quenching technology to improve the fatigue strength through refinement of the microstructure. CAI Z $\mathrm{P}^{[10]}$ find there is a significant decrease on residual stress by combined the treatment of a pulsed magnetic field and a pulse current on steel samples. Zhichao $\mathrm{Li}^{[11]}$ analyzed the influence of quenching rate on residual stress and deformation though computer simulation.

In recent years, domestic experts and scholars have also made many research results in heat treatment. Hong Lai ${ }^{[12]}$ used ANSYS software to simulate the quenching temperature field of workpiece with complex structure. Peng Huang ${ }^{[13]}$ built a $2 \mathrm{D}$ finite element model to study the influence of the heat exchange surface to heat transfer coefficient. Wei Liu ${ }^{[14]}$ study the influence of strain rate on strain induced $\alpha^{\prime}$-martensite transformation by tensile testing. Lianfang $\mathrm{He}^{[15]}$ found that the transformation plasticity caused the irregular distortion of workpiece by the quenching software developed by himself. Chunhuai Chen ${ }^{[16]}$ analyzed the process of quenching in the view of heat transfer theory and made some researches about the quenching medium's ability and the measurement methods. Lei Zhou ${ }^{[17]}$ studied the influence of heat treatment technology to bearing ring's microstructure and properties by electron microscopes, hardness testing and residual stress testing. Xia Miao ${ }^{[18]}$ compared and analyzed the bearing ring's residual stress after magnetic treatment, quenching, annealing and tempering by x-ray diffraction. Minglei $\mathrm{Li}^{\left[{ }^{[19]}\right.}$ simulated the hub bearing's whole process of quenching by DEFORM and analyzed the phenomenon appeared in quenching. Although, many researches made by the experts at home and abroad mainly concentrated on materials' quenching, there were only few people to study the actual workpiece of industrial production, especially in the bearing industry.

In this paper, the finite element analysis software DEFORM was used to analyze the quenching and DCT of YRT inner ring. The change rule of temperature field, organization field and stress-strain field of inner ring specimen during the quenching and DCT were discussed, and then, the hardness, residual austenite and residual stress of YRT80 inner ring after the quenching and DCT are analyzed and forecasted.

\section{The structure and heat treatment process route of bearing inner ring specimen}

YRT80 is a two-way thrust roller bearing with three rows of raceway, the geometry structure is complex. The structure of the bearing inner ring is shown in Fig.1, the major parameters are shown in Tab.1.
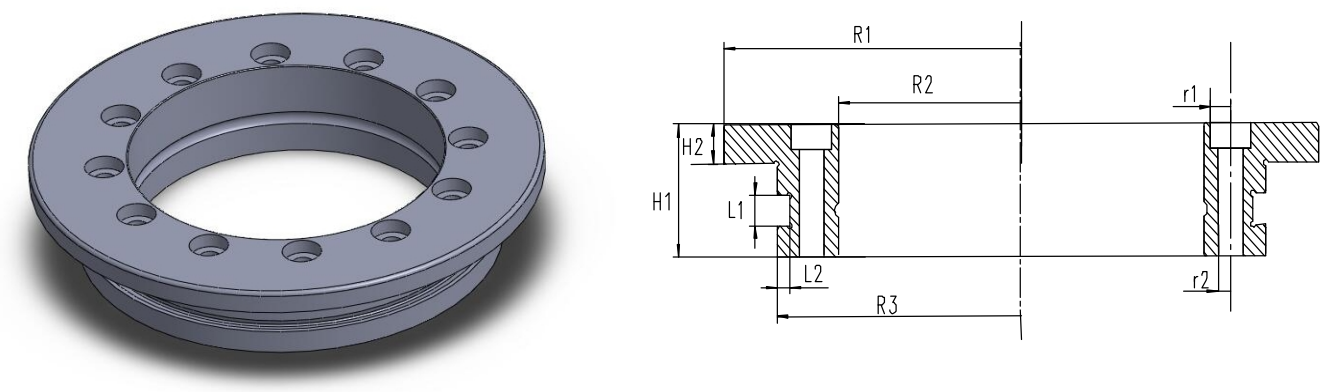

Fig.1 Geometry and dimensions of YRT80 inner ring 
The process route of interrupted quenching of inner ring specimen is shown in Fig.2: Firstly, inner ring specimen is heated up to $850^{\circ} \mathrm{C}$ and preserved for $40 \mathrm{~min}$ until the microstructure entirely convert to austenite; Secondly, the temperature of specimen is reduced to $55^{\circ} \mathrm{C}$ by oil quenching and to the ambient temperature by air cooling; Thirdly, putting inner ring specimen in the cold chamber for DCT, the specimen is take out until the temperature is cold down to $-70^{\circ} \mathrm{C}$, and then re-warmed under the ambient temperature.

Table. 1 The major parameter ofYRT80 inner ring

\begin{tabular}{|c|c|}
\hline Items & Values $/ \mathrm{mm}$ \\
\hline External diameter,R1 & 65.0 \\
\hline Inner diameter,R2 & 40.0 \\
\hline Inner ring diameter, R3 & 53.5 \\
\hline Big pitch diameter, $\mathrm{r} 1$ & 8.0 \\
\hline Small pitch diameter ,r2 & 3.0 \\
\hline Pocket hole width, L1 & 28.65 \\
\hline Pocket hole depth, L2 & 6.65 \\
\hline Bearing thickness, H1 & 5.0 \\
\hline Outer ring thickness, H2 & 2.8 \\
\hline Material & GCr15 \\
\hline
\end{tabular}

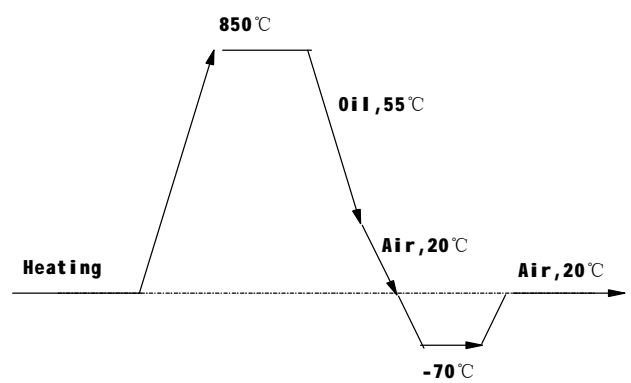

Fig.2 schematic diagram of heat treatment process

\section{The numerical simulation of quenching and DCT}

This finite element analysis software DEFORM was used to analyze the quenching and DCT of YRT80 inner ring specimen. In consideration of the geometrical symmetry and complexity of inner ring specimen, only the one-twelfth geometrical model was built and saved as STL format in SolidWorks software in order to improve the simulation efficiency, and then imported into DEFORM. The 3-D finite element model of inner ring is shown in Fig.3, and the number of tetrahedral mesh and node is 36064 and 168374, respectively. In order to accurately simulate the process of quenching and DCT, the temperature change of each step is set to $5^{\circ} \mathrm{C}$ and the variation of time step is set to $0.001 \sim 10 \mathrm{~s}$ in DEFORM.

The relevant parameters of inner ring specimen during the quenching and DCT are shown as follows:

(1) The ambient temperature was set to $20^{\circ} \mathrm{C}$, oil temperature was set to $55^{\circ} \mathrm{C}$, and the temperature of cold chamber was set to $-70^{\circ} \mathrm{C}$;

(2) As the key factors of microstructure changes, the convective heat transfer coefficient during quenching and DCT is different due to the different kinds of quenching oil. The quenching oil in 
this paper refer to Ref.[20], and the convective heat transfer coefficient at different temperature of quenching oils as shown in Fig.4. The convective heat transfer coefficient of DCT was set to 0.05.

(3) In the process of simulation, GCr15 was seen as a combination of austenitic, pearlite, bainite and martensite according to Ref.[21], the elasticity modulus, poison's ratio, coefficient of thermal expansion, heat conductivity coefficient and yield strength of which are shown in Tab.2.
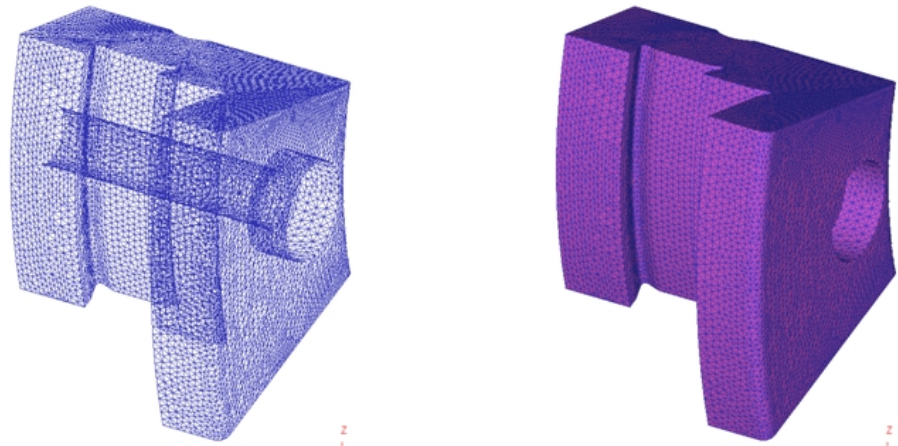

Fig.3 Three-dimensional finite element model of inner ring specimen

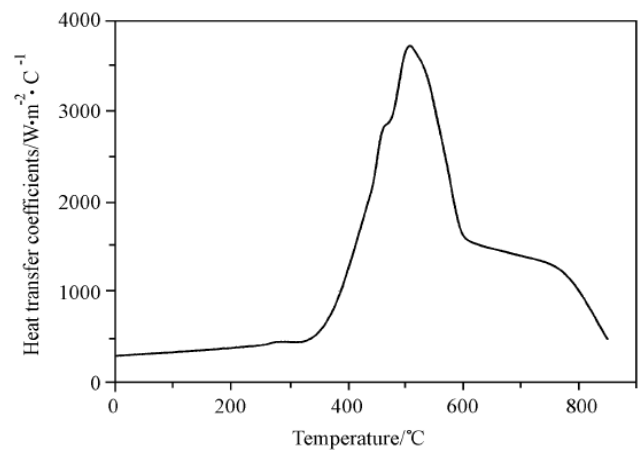

Fig.4 Heat transfer coefficient of quenching oil

Table. 2 Thermo-physical parameters of GCr15

\begin{tabular}{|c|c|c|c|c|c|c|}
\hline \multirow{2}{*}{ Temperature $/{ }^{\circ} \mathrm{C}$} & \multicolumn{2}{|c|}{$\begin{array}{c}\text { Elasticity modulus, } \\
\text { E/GPa }\end{array}$} & \multicolumn{2}{|c|}{ Poisson's ratio, $\mu$} & \multicolumn{2}{|c|}{$\begin{array}{c}\text { Coefficient of thermal expansion, } \\
\alpha / 10^{-5} \mathrm{C}^{-1}\end{array}$} \\
\hline & Austenitic & Martensite & Austenitic & Martensite & Austenitic & Martensite \\
\hline $25^{\circ} \mathrm{C}$ & 201 & 210 & 2.370 & 1.209 & 2.370 & 1.209 \\
\hline $100^{\circ} \mathrm{C}$ & 195 & 207 & 2.367 & 1.244 & 2.367 & 1.244 \\
\hline $300^{\circ} \mathrm{C}$ & 177 & 193 & 2.364 & 1.314 & 2.364 & 1.314 \\
\hline $500^{\circ} \mathrm{C}$ & 159 & - & 2.361 & - & 2.361 & - \\
\hline $700^{\circ} \mathrm{C}$ & 140 & - & 2.360 & - & 2.360 & - \\
\hline $900^{\circ} \mathrm{C}$ & 121 & - & 2.361 & - & 2.361 & - \\
\hline
\end{tabular}

\begin{tabular}{|c|c|c|c|c|}
\hline \multirow{2}{*}{ Temperature ${ }^{\circ} \mathrm{C}$} & \multicolumn{2}{|c|}{$\begin{array}{c}\text { Heat conductivity } \\
\text { coefficient, } \lambda / \mathrm{Wm}^{-1} \mathrm{C}^{-1}\end{array}$} & \multicolumn{2}{c|}{ Yield strength/MPa } \\
\cline { 2 - 5 } & Austenitic & Martensite & Austenitic & Martensite \\
\hline $25^{\circ} \mathrm{C}$ & 17.05 & 37.49 & 444 & 2108 \\
\hline $100^{\circ} \mathrm{C}$ & 17.95 & 39.03 & 443 & 2107 \\
\hline $300^{\circ} \mathrm{C}$ & 20.35 & 39.68 & 365 & 1986 \\
\hline $500^{\circ} \mathrm{C}$ & 22.74 & - & 160 & - \\
\hline $700^{\circ} \mathrm{C}$ & 25.13 & - & 82 & - \\
\hline $900^{\circ} \mathrm{C}$ & 27.52 & - & 50 & - \\
\hline
\end{tabular}




\section{The results and discussions}

\section{Temperature change during quenching}

As shown in Fig.5, five points locate in different areas of specimen are used to analyze the heating, cooling, microstructure changes and stress changes during quenching. The five points P1, P2, P3, P4 and P5 locate at the core, the center of outer wall, the center of inner wall, the center of raceway and the thin wall of bolt hole, respectively.

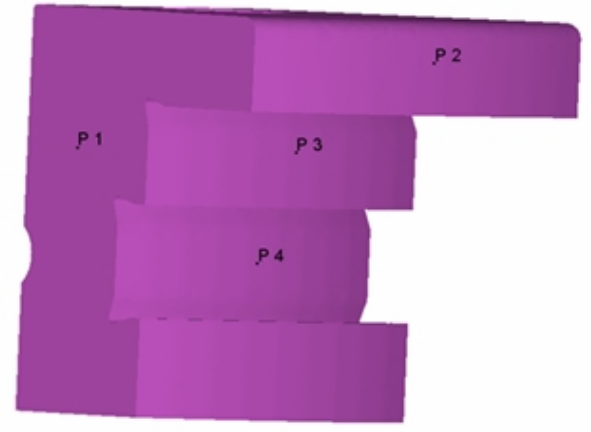

(a) Front view

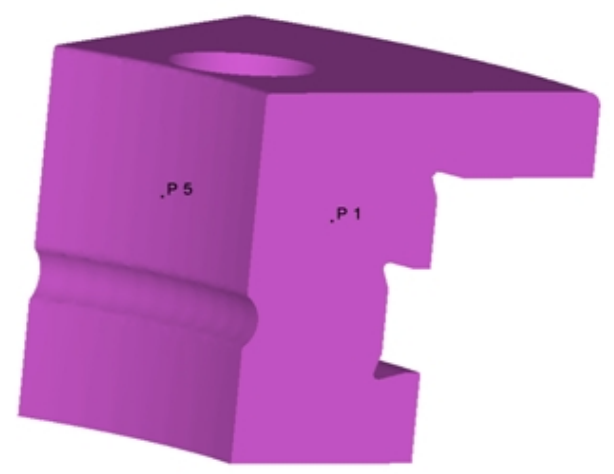

(b) Side view

Fig.5 Five points of YRT80 inner ring specimen

The temperature changes of five points are shown in Fig.6, it can be seen that the change rule of temperatures of five points are different. In the process of temperature rise, the temperature difference of five points is small, but in the process of oil quenching, specimen is rapidly cold that leads to the great difference of cooling behavior among the five points. Cooling speeds at P1 and P4 are the slowest and the fastest, respectively. According to the above-mentioned analysis, it can be seen that the geometric shape of inner ring is one of the important factors which cause the temperature difference in the process of quenching. However, in the process of DCT, the cooling curve is relatively gentle because of the relatively gentle heat transfer, and then the temperature difference among five points is not significant.

According to the cooling curves of five points in Fig.6, it can be seen that the process of quenching and DCT can be divided into three stages: steam film cooling stage, boiling cooling stage and Convection cooling stage. As shown in Fig. 6, the temperature of first stage is in the range of $850^{\circ} \mathrm{C} \sim 600^{\circ} \mathrm{C}$, because the surface temperature of specimen is much higher than quenching oil, there is a layer of steam film on the surface of specimen which can prevent quenching oil contact with the specimen, thereby lower the heat exchange rate; The temperature of second stage is in the range of $600^{\circ} \mathrm{C} \sim 400^{\circ} \mathrm{C}$, with the decrease of specimen's temperature, the steam film gradually begins to burst, and then the specimen's surfaces slowly begin to contact with quenching oil. In this stage, the cooling rate reaches the extreme because the bursting bubbles take away a lot of heat; In the third stage, the temperature is in the range of $400^{\circ} \mathrm{C} \sim 20^{\circ} \mathrm{C}$, when the specimen's temperature is below the boiling point of quenching oil, the cooling rate of specimen trends to be stable. In this stage, the cooling rate is mainly influenced by two factors: on the one hand, the decrease of temperature difference between specimen and quenching oil lower the heat exchange efficiency; On the other hand, lots of latent heat of phase change product by austenite to martensite also affects the cooling efficiency. The three stages in the process of quenching are not completely independent, they may happen in the different areas at the same time due to the complexity geometric structure 
and the different temperature in different areas. In the process of DCT, the natural heat exchange rate is much slower than that in the process of oil quenching, because DCT is the typical process of boiling heat transfer.

The temperature change is one of the important criteria of heat treatment in the whole process. The temperature change curve and temperature difference curve are shown in Fig.6 and Fig.7. In Fig.7, it can be seen that the biggest temperature difference can reach $305^{\circ} \mathrm{C}$ in the process of quenching, but the temperature difference between $\mathrm{P} 1$ and $\mathrm{P} 4$ in the process of DCT is only $2^{\circ} \mathrm{C}$. The gradient of temperature difference in the process of oil quenching is far greater than that in the process of DCT.

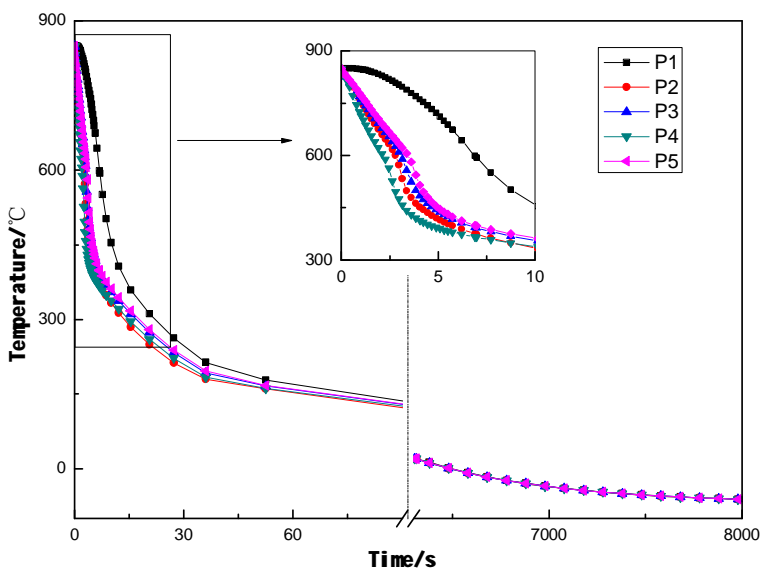

Fig. 6 The temperature curve of five points during quenching

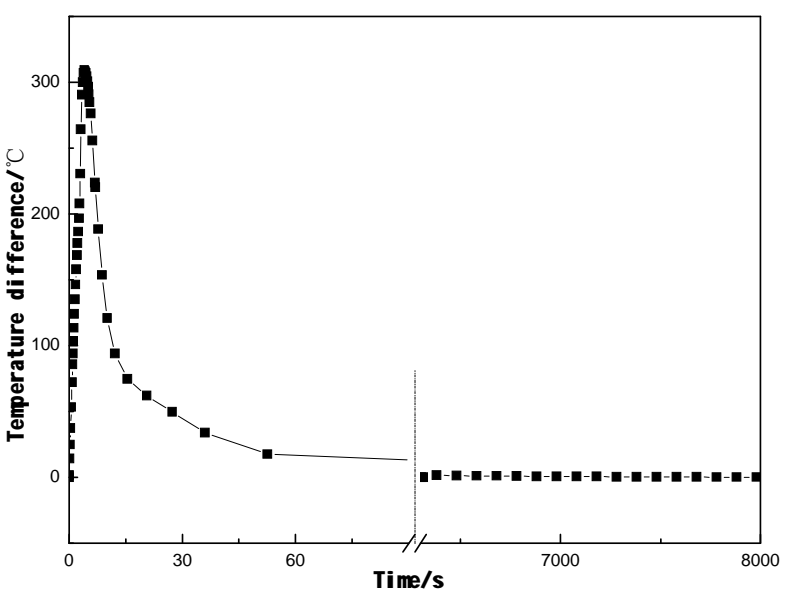

Fig. 7 Temperature difference between P1 and P4 during quenching

\section{Microstructure changes of YRT80 inner ring}

Inner ring specimen usually have a lot of residual austenite after the traditional quenching which will reduce the surface hardness, wear resistance, the size precision and stability, and the fatigue life, therefore, the specimen with high precision should reduce the amount of austenite. However, little residual austenite can enhance the intensity and ductility, reduce the contact stress concentration, and improve the fatigue life of specimen.

The change curves of austenite and martensite at five points are shown in Fig.8. Due to the difference among the cooling speeds in different areas of inner ring, the forming times of martensite in different areas are different. P2 is the first point to form martensite at 39 second. P1 is the slowest area to form martensite at 61 second. After cooling to the ambient temperature, the percentages of 
martensite and residual austenite in Fig.9 are about $94.0 \%$ and $6.0 \%$, respectively. After DCT, austenite can further convert into martensite, and the phase transformation rate in the process of DCT is much less than that in the process of oil quenching. Finally, the percentage of martensite and residual austenite remains $98.7 \%$ and $1.3 \%$, respectively. The portable X-ray residual stress analyzer is applied to measure the amount of residual austenite before and after DCT, which are 6\% and $1.4 \%$, respectively. According to the above-mentioned analysis, the simulation results are consistent with the testing results, which also show the correctness of the numerical simulation.

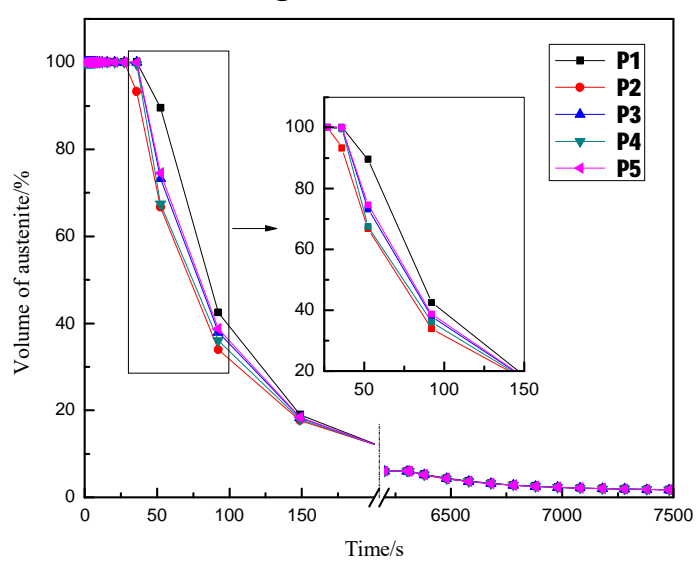

(a)Austenite

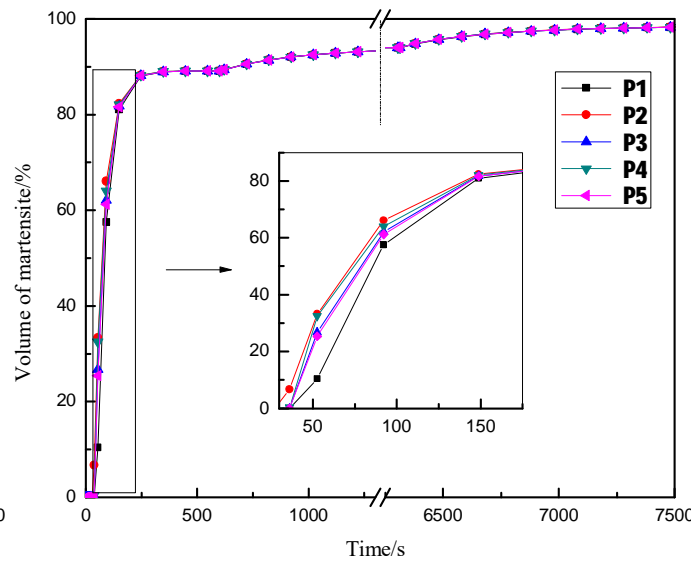

(b)Martenite

Fig.8 Microstructure evolution at characteristic point of YRT80 specimen during quenching and DCT

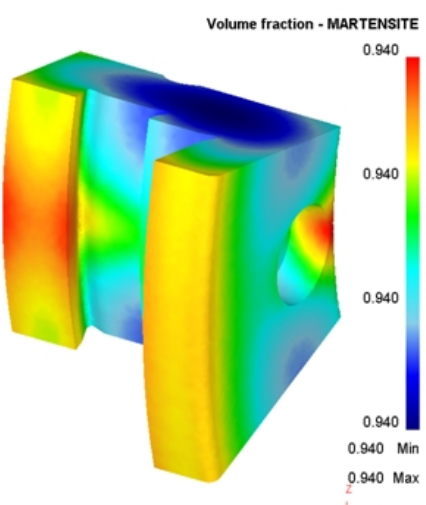

(a) Oil quenching

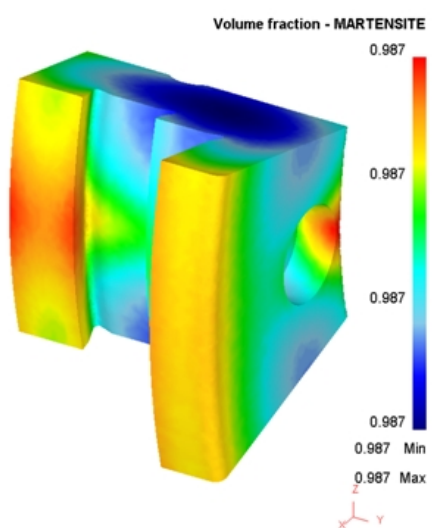

(b)DCT

Fig.9 Martensite distribution of YRT80 inner ring

The hardness distributions after oil quenching and DCT are shown in Fig. 10, the whole hardness is 64.9HRC after oil quenching and up to 67.3HRC through DCT. In generally, the specimen's hardness mainly depend on amount of martensite and its hardness, DCT can further promote the austenite convert into martensite. That can analyze why the specimen's hardness is further promoted through DCT. 


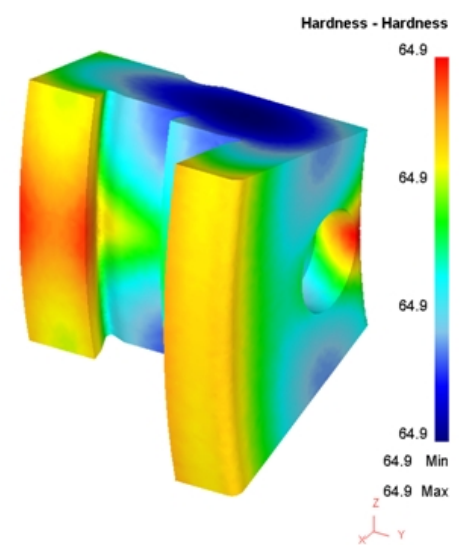

(a)Oil quenching

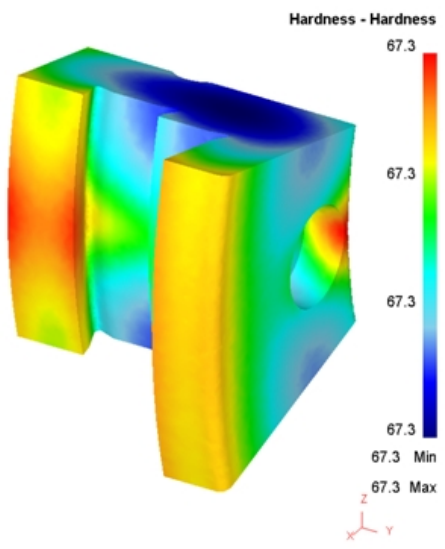

(b)DCT

Fig.10 Hardness distribution of YRT80 inner ring

\section{Stress analysis}

In order to obtain the ideal hardness and wear-resistance, the oil quenching and DCT for the YRT80 inner ring is indispensable. However, due to the inevitable internal stress aroused by oil quenching and DCT, the unreasonable structure and heat treat process would both cause the greater internal stress from quenching. If the internal stress overtakes the material's yield strength and fracture strength, the distortion and cracking of work-piece may happen. The internal stress caused by the thermal stress and microstructure changes in the process of oil quenching and DCT, and satisfies vector superposition principle, and the studies about the change trend and influence factors of stress-strain in the process of oil quenching and DCT are indispensable.

Because the internal stress caused by DCT is much less than that caused by oil quenching, in this paper, only the internal stress caused by oil quenching is analyzed. The change curves of equivalent stress at five points are shown in Fig.11. In Fig.11, there are two stress peaks in the process of quenching, which appears in about $4 \mathrm{~s}$ and 52s, respectively. According the comparison of Fig. 7 and Fig.11, the temperature of specimen reduces rapidly at 3 second, at this moment the temperature difference reach $305^{\circ} \mathrm{C}$ which is the maximum temperature difference in the process of oil quenching. However, at this moment, the specimen's temperature is not lowered below the phase transformation temperature $\mathrm{M}_{\mathrm{s}}$, and the phase transformation hasn't started, so that the first stress peak is mainly caused by thermal stress; At 52 second, the specimen's temperature is lowered below the phase transformation temperature $\mathrm{M}_{\mathrm{s}}$, the austenite begins to convert into martensite at this time. Because the volume of martensite with unit mass is bigger than that of austenite, when the phase transform is happening, it causes volume expansion of specimen which may cause the greater structural stress. However, at this time, the temperature difference is only $50^{\circ} \mathrm{C}$ which only causes a small thermal stress. Therefore, the second stress peak is mainly caused by the structure stress. 


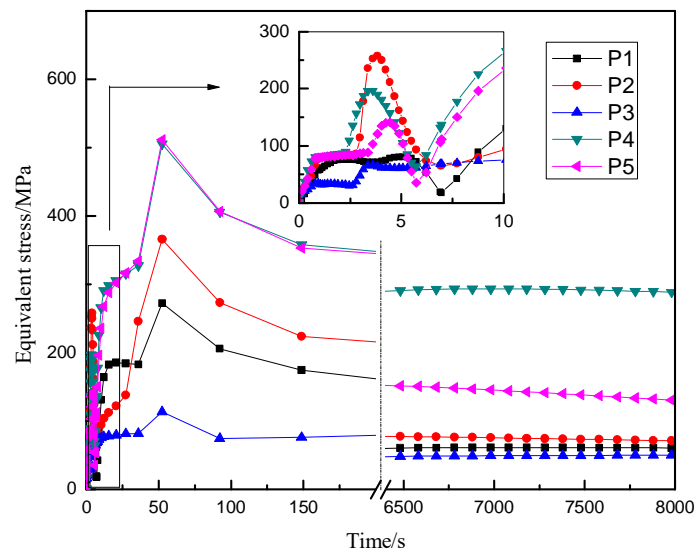

Fig.11 Change curves of equivalent stress during oil quenching and DCT

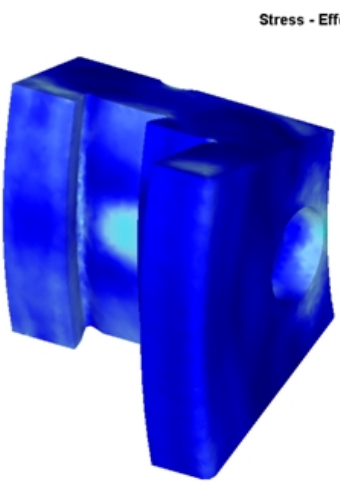

(a)Oil quenching

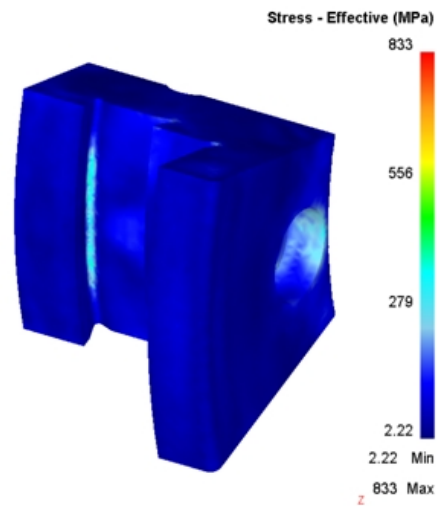

(b)DCT

Fig.12 Residual stress distribution contour of YRT80 inner ring

The residual stress distributions of specimen after oil quenching and DCT are shown in Fig.12, the residual stress can be further reduced through DCT. In Fig.12, the residual stress mainly concentrates in the vicinity of bolt-hole and groove of inner ring. The reasons of above-mentioned symptoms can be contributed that: Due to the various cooling rates in different areas, the austenite of specimen's external wall is prior to convert into martensite, and the yield strength of martial at the ends of specimen increases with the temperature decreasing. With the cooling happening, the stress caused by microstructure changes in the core of specimen can not lead to the plastic deformation of specimen's outer surface, and then the core of specimen would be acted by the compressive stress, which is named residual stress. According to the comparison of Fig.9 and Fig.12, there is a significant connection between residual stress and the percentage of martensite. The residual stress in the areas where have more residual austenite is higher, and the residual stress in the area where have more residual martensite is smaller. The residual stress is lowered $9 \%$ through DCT, which improve the service life of inner ring. And it must point out that a certain amount of residual stress can also improve the wear-resisting property and fatigue strength.

\section{Conclusions}

(1)Due to the complexity of YRT80 inner ring's structure, the cooling rate in different areas has an obvious difference. The cooling rate decreases with the wall thickness increasing. The maximum temperature difference among different areas in the process of oil quenching is up to $305^{\circ} \mathrm{C}$, but less than $2^{\circ} \mathrm{C}$ in the process of DCT. 
(2)In the process of quenching, the various cooling rates are the mainly factor which leads to the difference of microstructure changes. The cooling speed is the fastest in the vicinity of bolt-hole where the austenite transforms into martensite firstly, and the slowest cooling speed happen in the core of specimen. Through DCT, the amount of residual austenite is remarkably reduced, and specimen's hardness is further improved.

(3)In the process of quenching and DCT, stress is mainly caused by thermal stress and microstructure stress. The stress in the process of oil quenching is mainly affected by the thermal stress, but the stress in the process of DCT is mainly affected by microstructure stress. And stress in the process of DCT is much less than that in the process of oil quenching.

(4)The residual stress mainly concentrates in the vicinity of bolt-hole and groove of inner ring, decreases with the amount of residual martensite increasing, and increases with the amount of residual austenite increasing. And a certain amount of residual stress can improve the wear-resisting property and fatigue strength.

\section{Acknowledgments}

This research is financially supported by Major science and technology project in Luoyang (1501008A), China.

\section{References}

[1] Stickels C A. Plastic deformation of quenched and tempered 52100 bearing steel in compression[J]. Metallurgical and Materials Transactions A, 1977, 8(1):63-70.

[2] Kwun S I, Fournelle R A. Low cycle fatigue behavior of a quenched and tempered niobium bearing HSLA steel[J]. Metallurgical and Materials Transactions A, 1980, 11(8):1429-1437.

[3] Kwun S I, Fournelle R A. Fatigue crack initiation and propagation in a quenched and tempered niobium bearing HSLA steel[J]. Metallurgical and Materials Transactions A, 1982, 13(3):393-399.

[4] Denis S, Gautier E, Simon A, et al. Stress-phase-transformation interactions-basic principles, modeling and caculation of internal stresses[J]. Materials Science and Technology,1985, 1(10):805-814.

[5] Lisic B, Fietin T. Computer-aided evaluation of quenching intensity and prediction of hardness distribution[J].Heat Treat, 1988,5(2):115-124.

[6] CHANG H, SCHOENIG F C, SOULES J A. Eddy current offers a powerful tool for investigating residual stress and other metallurgical properties[J]. Materials Evaluation,1999, 57(12):1257-1260.

[7] Gur C H, Tekkaya A E. Numerical investigation of non-homogeneous plastic deformation in quenching process[J]. Materials Science and Engineering, 2001,319(312):164-169.

[8] Simsir C, Gür G H.3D FEM simulation of steel quenching and investigation of the effect of asymmetric geometry on residual stress distribution [J].Materials Processing Technology,2008, 207(1-3):168-186.

[9] Lee K O, Hong S K, Kang Y K, et al. Grain refinement in bearing steels using a double-quenching heat-treatment process[J]. International Journal of Automotive Technology, 2009, 10(6):697-702.

[10] CAI Z P, HUANG X Q. Residual stress reduction by combined treatment of pulsed magnetic field and pulsed current[J]. Materials Science and Engineering. A, Structural Materials : Properties, 
Microstructure and Processing,2011,528(19-20):6287-6292.

[11] Zhichao Li, B.Lynn Ferguson. Effect of quenching rate on distortion and residual Stress during induction hardening of a full-float truck axle shaft[J]. JMEPEG, 2014,23:4170-4180.

[12] Hong Lai, Tianmo Liu. Temperature filed ansys simulation in quenching process of 45 teel part[J]. Journal of Chong qing University, 2003, 26(3):82-84[in Chinese].

[13] Peng Huang, Xingzhao Wei, Xiahong Dong, Yuhui Su. Investigation of Influence of different surface to heat transfer coefficient during guenching by finite element method[J]. Heat Treatment Technology and Equipment. 2007,28(3):15-19[in Chinese].

[14] Wei Liu, Zhibin Li, Xiang Wang. Effect of strain rate on strain induced $\alpha$ '-martensite transformation and mechanical response of austenitic stainless steels[J]. Acta Metallurgica Sinica., 2009.45(3),285-291[in Chinese].

[15] Lianfang He, Huiping Li, Guoqun Zhao, FEN simulation of temperature, phase-transformation and stress/strain in quenching process[J]. Transaction of Materials and Heat Treatment. 2011,32(1):128-133[in Chinese].

[16] Chunhuai Chen, Jingen Zhou, etc. Measurement and application of cooling power of quenchants. [J].Matel Heat Treatment, 2011, 26(11): 28-31[in Chinese].

[17] Lei Zhou, Xiujuan Zhao, Cunhuan Chen, etc. Effect of heat treatment processes on quenched microstructure and properties of GCr15 steel bearing outer rings[J]. Physical and Chemical testing: physical handbook, 2013, 49(10) [in Chinese].

[18] Xia Miao, Dongsheng Qian,Yanli Song, etc. Influence rule of steel GCr15 in process of cold ring rolling-quenching by magnetic treatment[J]. Journal of Mechanical Engineering, 2014, 50(16):112-118[in Chinese].

[19] Minglei Li, Hongye Liu, Kaiwen Deng. Numerical simulation on overall quenching process for outer rings of hub bearings.[J]. Bearing, 2016(7):26-31[in Chinese].

[20] Shanting Niu, Guoqun Zhao, Huiping Li. The application of finite element based optimization methods in inverse heat conduction analysis of three-dimensional quenching process[D]. Shandong university, 2007[in Chinese].

[21] Xin Yao, Jianfeng Gu, Mingjuan Hu, Weimin Zhang.Numerical simulation of the quenching process of GCr15 steel tube. [J]Transaction of Materials and Heat Treatment, 2003, 24(1): 78-81[in Chinese]. 